\title{
A Mixture of Distributions Model for the Term Structure of Interest Rates with an Application to Risk Management
}

\author{
Michael Jacobs, Jr. ${ }^{1}$ \\ Accenture Consulting \\ michael.a.jacobs@accenture.com
}

\begin{abstract}
It is well known in the term structure literature that the normal and log-normal distribution models are not consistent across high and low interest rate regimes, which creates challenges for building models to measure and manage interest rate risk. In this paper we outline a tractable approach to solving this problem based upon the theory of Black (1995), which utilizes an "inverse-call transformation" methodology to derive "shadow rates" as underlying drivers of observed yields, that have been shown in the literature to be more appropriate than the standard models for the purposes forecasting and risk management with respect to interest rate sensitive portfolios. We extend the literature by calibrating optimal shadow rates, modeling them in a multivariate dynamic conditional correlation (DCC) framework and applying the results to an interest rate risk management exercise, thereby providing a useful risk management tool for both banks and their prudential supervisors. We conclude that our mixture of normal and log-normal distributions model, utilizing optimally calibrated shadow rates as drivers, produces the most reasonable set of simulated 1 year rate distributions from the fitted DCC model as compared to the normal or log-normal model.
\end{abstract}

Keywords: Interest Rate Risk, Term Structure, DCC, Shadow Rates, Fisher Black, CoxIngersoll-Ross Model

JEL Classification: C15, C22, E43, G17

\section{INTRODUCTION}

It is and has been the practice in the valuation of interest derivatives to model the nominal and not the real interest rate process. This assumes some exogenous stochastic process, ignoring the underlying factors that likely influence the interest rate, such as expected inflation or the market for capital (Black, 1976). The most prevalent choices in practice have been the normal process (Vasicek, 1977) or a lognormal processes (Dothan, 1978), while primarily in the academic realm we also have seen the square-root process (Cox et al, 1985). In the case of the normal model, the volatility of the change in the interest rate does not depend upon the level of the rate, while with the lognormal model it is the volatility of the proportional change in the interest rate that is independent of the level. Alternatively, in the square-root model we have the ratio of the variance of the change in the interest rate to the rate does not depend upon the level of the rate, implying that the volatility of the change in the rate is proportional to the square root of the rate. We can put mean reversion into any of these processes. The normal process has been criticized in that counterintuitively it assumes that the interest rate volatility does not decline as the rate approaches zero. While the latter may be innocuous in practice if rates are far from zero, a more serious conceptual critique is that a normal distribution admits negative nominal interest rates, although the probability of that occurring may in many applications be minimal. Furthermore,

1 Corresponding author: Michael Jacobs, Jr., Ph.D., CFA, Principal Director, Accenture Consulting, Finance and Risk Services Advisory / Models, Methodologies \& Analytics, 1345 Avenue of the Americas, New York, N.Y., 10105, 917-324-2098, michael.a.jacobs@accenture.com. The views expressed herein are those of the author and do not necessarily represent a position taken either by Accenture nor any affiliated firms. 
while at one time it was the economic wisdom that nominal interest rates should never be negative (Black, 1976), we observe currently that negative nominal interest rates are in fact rather prevalent at this time outside the United States (Risk 1015; 1016 a,b,c).

A lognormal distribution for the nominal interest rate implies that it can assume a value of zero, which one can argue is unrealistic, as in the U.S. last observed this only as far back as during the Great Depression. This is a consequence of that in a lognormal process volatility declines rapidly as the random variable approaches zero, which is somewhat at odds with stylized empirical facts. On the other hand, the somewhat more complex square root process lies somewhere between the normal and lognormal cases in terms of the constraints at this boundary, since as when mean reversion is strong enough, the rate interest rate is precluded from reaching zero. However, there exist other cases in which the rate can reach zero, but depending on the parameter settings this could be either a reflecting or an absorbing barrier. In terms of economic intuitiveness, probably the absorbing barrier is more palatable, as the as such a bounce is hard to rationalize, but then in the absorbing case we need to think carefully about what economic mechanism would reestablish the non-perverse situation of positive nominal rates.

The economic intuition underlying why the short rate cannot be negative is grounded in the fact that we always have an option to hold currency when a short bond (or bank account) has a negative yield. Therefore we can consider the short rate itself as an option and we can specify a process that replaces all the negative rates with the value of zero. Following Black (1995), we term this state variable the "shadow short rate."

Note that we can use any of the three processes discussed herein in to model the shadow rate, but if we use a lognormal or square root process, we will employ "shifted" versions of those processes in order to capture negative values. This procedure will likely rule out analytic solutions for the prices of interest rate derivatives, but we can accommodate this through numerical solutions if we are able to deal with the computational complexity. It would seem then that the normal distribution is a convenient assumption for the shadow rate.

Although the short rate can be zero while the shadow short rate is negative, no longer term rate can be zero as long as there is a non-zero probability that the short rate can become positive again. In pricing interest rate derivatives on a tree having finite interval size, while longer term rates may be zero along certain paths, each rate converges to positive values as the interval size approaches zero. Said differently, in states of the world where interval sizes should not matter, the only sensible equilibrium stipulates that all longer term rates should be positive. Therefore, any forward rate is an option on the shadow rate, as the short rate at a future time is the maximum of zero and the shadow rate. It follows that some of the usual sensitivities hold, such that the forward rate as an option value is increasing in the level or volatility of the current shadow rate. However, the effect of increasing maturity is ambiguous, since the effects of drift comes into play, and also that convexity depresses forward rate beneath expected short rates.

When the shadow rate is well above zero, especially when the interest rate shows strong mean reversion, none of this matters much. However, when the shadow rate is near zero or negative, this results in an upwardly sloping yield curve. Then as we increase maturity, the effective volatility increases, and therefore the forward rate increases. Due to this convexity, the yield curve tends to be concave downward. When we put no floor on the short rate, the yield curve crosses zero and becomes negative at a long maturity of 26 years. Putting a floor of zero on the short rate causes the yield curve to rise at first, and then declines at long maturities.

These observations are consistent with the consensus in the term structure literature that the normal and log-normal distribution models are not consistent across high and low interest rate regimes. Obviously, this creates challenges for building models to measure and manage interest rate risk. In this paper we develop a tractable approach to solving this problem, based upon the model of Black (1995), which utilizes an "inverse - call transformation" methodology to derive the shadow rates as the state variable underlying the observed term structure of interest rates. Shadow rates have been show in the literature to be more appropriate than the standard models for the of forecasting and risk management 
with respect to interest rate sensitive portfolios (Loregian and Meucci, 2016). We extend the literature by optimally calibrating shadow rates, modeling them in a multivariate dynamic conditional correlation (DCC) framework and applying the results to an interest rate risk management exercise. This exercise provides a useful risk management tool for both banks and their prudential supervisors.

This paper shall proceed as follows. Section 2 review the literature. In Section 3 we present our model. Section 4 contains our empirical implementation of this model, including an optimal calibration of the shadow rate, as well as a simulation of the distribution of yields using a DCC econometric model. Finally, Section 5 concludes and provides direction for future research.

\section{REVIEW OF THE LITERATURE}

Modeling the process followed by the term structure of interest rates is of critical in two domains of finance, the pricing of interest rate dependent contingent claims (bonds and derivatives) under risk-neutral measure, and the management of interest rate risk under actuarial measure. We observe that across these two applications there are tremendous differences in the modeling techniques in terms of mathematical complexity. The state of the modeling in the bond and interest rate derivatives pricing literature is rather advanced, while the models on the risk management side continue to be rudimentary.

The early standard of the pricing industry has evolved from spot rate models of having single factors (e.g., the mean reverting models of Vasicek (1977) and Cox, Ingersoll, and Ross (1985)), multiple factors (e.g., the affine models of Duffie and Kan (1996), Dai and Singleton (2000) and Duffee (2002); and generalizations thereof such as Collin-Dufresne and Goldstein (2002), Baliakin et al (2005), as well as Feunou and Meddahi (2009)). This has evolved to cutting edge approaches such infinite-dimensional models (Heath et al, 1992) and random fields (Goldstein, 2000). ${ }^{2}$

On the other hand, we observe in interest rate risk and portfolio management a thinner literature and more simplistic models, with the industry standard centered on nonparametric principal component decompositions of joint movements in interest rate term structures (e.g., Litterman and Scheinkman (1991), Bliss (1997) and Soto (2004)). In this paradigm, the two main approaches involve modeling either changes in either interest rates or their logarithms, the so-called "normal" and "log-normal" models for the term structure of interest rates. As elaborated upon in Black (1995), as well as recently by Loregian and Meucci (2016), these models are distinguished principally by the implications for the volatility of interest rate increments across the term structure: in the normal model, the volatility is independent of, whereas in the lognormal case, the volatility is proportional to the interest rate level. The normal model has the flaw that interest rates can be negative, which undesirable in low interest rate regimes, whereas the lognormal model is suitable to such environments (e.g., Japan since the mid-1990s and the United States since the financial crisis circa 2008). However, the log-normal model is known to underperform in high interest rate regimes, becoming susceptible to unrealistically high and explosive forecasts due to the exponential transformation.

Loregian and Meucci (2016) introduce a highly tractable methodology for the measurement of portfolio interest rate risk, and demonstrate that this is consistent and has favorable performance across different interest rate regimes, based upon an "inverse-call transformation" methodology developed by the authors to convert observed interest rates into "shadow rates". Herein we extend this methodology to the optimal calibration of shadow rates, and then modeling them in a multivariate DDC (Engle, 2002) framework, in order to generate predictive distributions of interest rates that can be applied in risk management and measurement.

\section{Model - The InVERSE CALl Transformation}

Let $Y_{t}(\tau)$ denote the yield to maturity of a zero-coupon bond at time $t$ with a given time to maturity of $\tau$. An empirical fact is that in high-rate regimes, the volatility of interest rate increments across the term structure is approximately independent of the interest rate level.

2 See Jacobs (2001) for an empirical comparison of spot- and forward- rate models, in the context of term structure and interest rate derivatives. 
This implies that increments of interest rates are approximately independently and identically distributed (i.i.d):

High Interest R ates $\Rightarrow Y_{t+\Delta t}(\tau)-Y_{t}(\tau) \sim I I D\left(\Theta_{\tau}\right)$

Where $\boldsymbol{\Theta}_{\tau}$ denotes a vector of parameters. It is rather common to assume an approximate Gaussian distribution, which has been shown to perform well in such regimes and has the benefits of tractability in pricing and applications, so that we have in most cases $Y_{t+\Delta t}(\tau)-Y_{t}(\tau) \sim N I D\left(\mu_{\tau}, \sigma_{\tau}\right)$, where NID denotes Normally and Identically Distributed, which we term the Normal Model ("NM"). Alternatively, in low-rate regimes the volatility of interest rate proportional increments across the term structure is approximately proportional to the interest rate level. Therefore, in this model percentage rate increments are approximately i.i.d.:

Low Interest Rates $\Rightarrow \frac{Y_{t+\Delta t}(\tau)-Y_{t}(\tau)}{Y_{t}(\tau)} \sim I I D\left(\Theta_{\tau}\right)$

Where again, we often choose the normality assumption, so that $\frac{Y_{t+\Delta t}(\tau)-Y_{t}(\tau)}{y_{t}(\tau)} \sim N I D\left(\boldsymbol{\Theta}_{\tau}\right)$.

As the increments approach zero, it follows that the logarithmic differences are normally distributed, which gives rise to the Log-Normal Model ("LM").

As the objective in the management of interest rate risk is to infer from history predictive distributions of future rates, the prevalent practice is to transform raw data into risk drivers, which are the variables that drive the P\&L of each rate dependent security in a portfolio. Such risk factors, denoted by $X_{t}(\tau)$, should be homogenous in distribution in order to be suitable for econometric modeling. In high-rate regimes, the fact that the volatility is approximately independent of the interest rate level suggests that the rates behave approximately like a random walk, and rates are the natural risk factors to be used in statistical analysis:

High Interest Rates Risk Driver $\Rightarrow X_{t}(\tau) \sim Y_{t}(\tau)$

Alternatively, in low-rate regimes the fact that the volatility is approximately proportional to the interest rate level suggests that the logarithm of the rates behave approximately as a random walk. Therefore, log-rates are the natural risk drivers to be used in econometric analysis:

Low Interest Rates Risk Driver $\Rightarrow X_{t}(\tau) \sim \ln \left(Y_{t}(\tau)\right)$

We know motivate and derive the inverse-call transformation as a means of deriving interest rate risk drivers that are conceptually sound under both regimes. The intuition behind this transformation follows from the fact that that the logarithmic function is the inverse of the exponential function. It follows that in low rate regimes we can write Equation 3.4 as $Y_{t}(\tau)=\exp \left(X_{t}(\tau)\right)$ and in high-rate regimes where rates are adequate risk drivers, so we can write Equation 3.3 as $Y_{t}(\tau)=I\left(X_{t}(\tau)\right)$, where $I(\cdot)$ denotes the identity function. In order to accommodate both of these regimes, we find a non-negative and increasing function, that to the exponential in the left tail, and similarly to the identity function in the right tail. We develop this function in the context of Black (1995), who interpreted observed interest rates $Y_{t}(\tau)$ as call options having zero strike prices on shadow rates $X_{t}(\tau)$, which live anywhere on the real line.

Therefore, we set $Y_{t}(\tau)=c_{\eta}\left(X_{t}(\tau)\right)$, where $c_{\eta}\left(X_{t}(\tau)\right)$ is the price of a zero-strike perpetual American call option on an asset following arithmetic Brownian motion process (Bachelier, 1900): 
$c_{\eta}\left(X_{t}(\tau)\right)= \begin{cases}X_{t}(\tau) & \text { if } X_{t}(\tau) \geq \eta \\ \eta \exp \left(\frac{X_{t}(\tau)}{\eta}-1\right) & \text { if } X_{t}(\tau)<\eta\end{cases}$

Where $\eta$ defines the threshold between low and high interest rate regimes, and can be viewed as a smoothing parameter that determines the shape of the call profile, converging to the maximum function as we shrink it to zero from above:

$\lim _{\eta \downarrow 0} c_{\eta}\left(X_{t}(\tau)\right)=\left(X_{t}(\tau)\right)^{+}$

The assumption of an arithmetic Brownian motion process is convenient due to tractability of the pricing formula is as well as that this allows shadow rates to lie anywhere on the real line (Liu 2007). The assumption of these dynamics also implies that shadow rates are approximately Gaussian, which is consistent with the empirical evidence presented herein.

The shadow rate can be interpreted as a "universal" risk driver (Loregian and Meuci, 2016) as it should have stable properties (i.e., invariance) across all interest rate regimes, both the high and the low that have been observed historically. We may derive these from the so-called inverse-call transformation (Loregian, and Meuci, 2016) through inverting Equation 3.5:

Table4.1. Summary Statistics of Daily U.S. Treasury Yields (1, 2 and 5 Year Maturities - January, 1990 to June, 2016)

\begin{tabular}{|l|l|l|l|}
\hline & 1 Year U.S. Treasury Yield & 2 Year U.S. Treasury Yield & 5 Year U.S. Treasury Yield \\
\hline Average & $3.2197 \%$ & $3.5497 \%$ & $4.2138 \%$ \\
\hline Standard Deviation & $2.3929 \%$ & $2.3941 \%$ & $2.1529 \%$ \\
\hline Minimum & $0.0800 \%$ & $0.1600 \%$ & $0.5600 \%$ \\
\hline $\mathbf{1 0}^{\text {th }}$ Percentile & $0.1700 \%$ & 0.38005 & $1.3700 \%$ \\
\hline $\mathbf{2 5}^{\text {th }}$ percentile & $0.5000 \%$ & $0.9200 \%$ & $2.2050 \%$ \\
\hline Median & $3.4600 \%$ & $3.9700 \%$ & $4.4800 \%$ \\
\hline $\mathbf{7 5}^{\text {th }}$ percentile & $5.3600 \%$ & $5.6200 \%$ & $5.9400 \%$ \\
\hline $\mathbf{9 0}^{\text {th }}$ percentile & $6.1200 \%$ & $6.4500 \%$ & $6.8700 \%$ \\
\hline Maximum & $8.6400 \%$ & $9.0500 \%$ & $9.1000 \%$ \\
\hline Coefficient of Variation & $74.32 \%$ & $67.45 \%$ & $51.09 \%$ \\
\hline Interquartile Range & $4.8600 \%$ & $4.7000 \%$ & $3.7350 \%$ \\
\hline Skewness & 0.0765 & 0.0538 & 0.0392 \\
\hline Kurtosis & -1.3012 & -1.2521 & -1.0536 \\
\hline
\end{tabular}

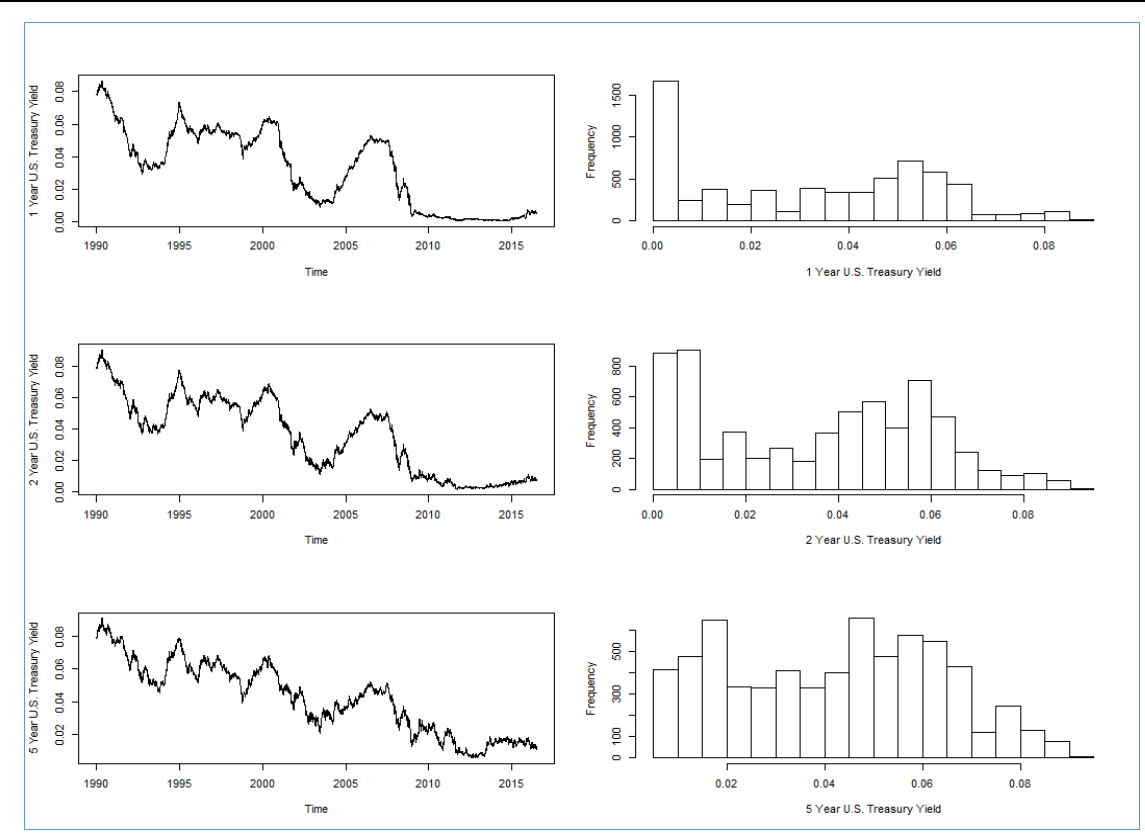

Figure4.1.Time Series and Data Histograms of Daily U.S. Treasury Yields (1, 2 and 5 Year Maturities - January, 1990 to June, 2016) 


$$
X_{t}(\tau)=c_{\eta}^{-1}\left(X_{t}(\tau)\right)= \begin{cases}Y_{t}(\tau) & \text { if } X_{t}(\tau) \geq \eta \\ \eta\left(\ln \left(\frac{Y_{t}(\tau)}{\eta}\right)+1\right) & \text { if } X_{t}(\tau)<\eta\end{cases}
$$

Loregian and Meucci (2016) note that negative interest rates may be accommodated through application of the shift operator $c_{\eta}^{-1}\left(X_{t}(\tau)\right) \leftarrow c_{\eta}^{-1}\left(X_{t}(\tau)-\underline{X}_{t}(\tau)\right)$ for a suitable lower bound $\underline{X}_{t}(\tau)<0$. We note in this regard that this does not address the issue of negative real rates, as in this paradigm those are modelled as options, and are necessarily non-negative. As negative real rates are a reality in the modern economy, this is an issue left open for future research.

\section{EMPIRICAL IMPLEMENTATION}

We shall illustrate the application of our model by analyzing the history of daily nominal U.S. treasury yields, focusing on the short end of the yields curve with tenures of 1,2 and 5 years from 1990 until the middle of 2016. In Table 4.1 we tabulate the summary statistics, and in Figure 4.1 we plot the time series and histograms, of these rates. As expected, the term structure at this short end has on average been upward sloping, with average yields of $3.22 \%, 3.55 \%$ and $4.21 \%$ for the 1, 2 and 5 year tenor, respectively. We observe that there has been a fair amount in variation relative to the mean in yields over time, with minima (maxima) of $0.08 \%, 0.16 \%$ and $0.56 \%(8.64 \%, 9.05 \%$ and $9.10 \%)$ respectively for the 1,2 and 3 year maturities; and respective coefficients of variation of $74.3 \%, 67.5 \%$ and $51.1 \%$. There is significant rightward skew in the distributions, and this is increasing in tenor. The time series and histograms show that there have been three distinct regimes, the high rate environment of the early $80 \mathrm{~s}$, the medium rate period of the $90 \mathrm{~s}$ and the former portion of the earlier decade, and then the very low rates of the recent period since the financial crisis.
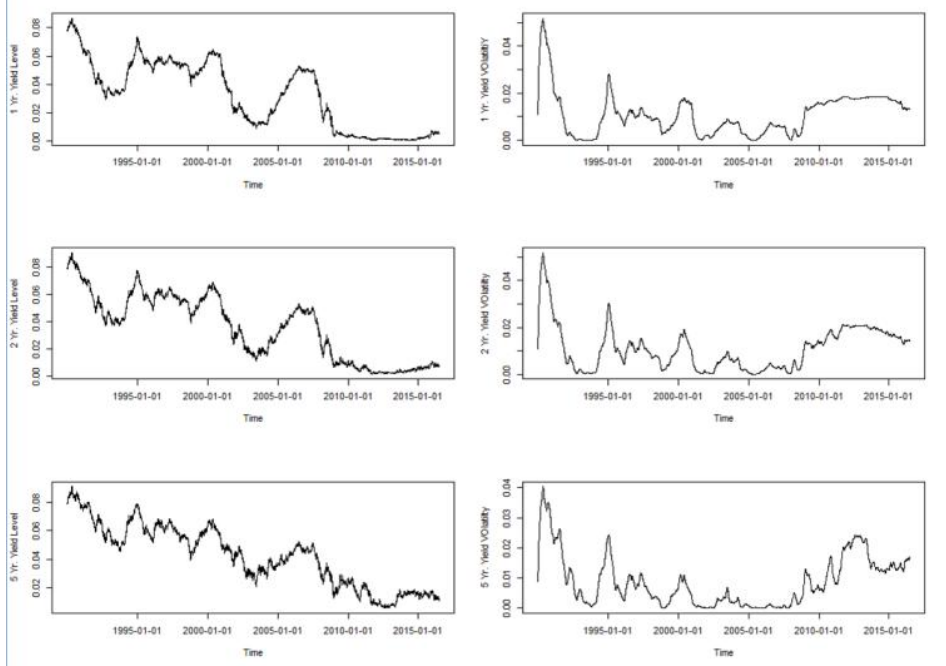

Figure4.2. Time Series and EWMA Volatilities of Daily U.S. Treasury Yields (1, 2 and 5 Year Maturities - January, 1990 to June, 2016)

In Figure 4.2 we plot the levels of the yields alongside their volatilities, where we proxy for the latter by a simple exponentially weighted moving average ("EWMA") measure, in which we choose the smoothing parameter according to the Risk Metrics ${ }^{\mathrm{TM}}$ parameterization of $\lambda=0.94$ (J.P. Morgan, 1996). While there is a a fair amount of noise in the estimated yield volatilities, we can see that as rates have declined in recent years this has been accompanied by a downward trend in volatility, where in earlier high rate regimes volatility has moved to a large degree independently of rates. We test this formally by performing a piece-wise regression of yield volatilities on rates interacted with an indicator for a high rate environment. We take the threshold for high rates from our calibration of a mixture of normal and log-normal distributions to yields, as we shall discuss in detail next, where the quantile is taken to the probability of being in a high interest rate regime. The results of these regressions (in which all estimates are statistically significant) 
Table4.2. Regression Analysis of Daily U.S. Treasury Yields Time Series and EWMA Volatilities of Yields (1, 2 and 5 Year Maturities - January, 1990 to June, 2016)

\begin{tabular}{|l|l|l|l|}
\hline & 1 Year U.S. Treasury Yield & 2 Year U.S. Treasury Yield & 5 Year U.S. Treasury Yield \\
\hline Intercept & 0.0033 & 0.0085 & 0.0043 \\
\hline Standard Error & 0.0002 & 0.0003 & 0.0004 \\
\hline P-Value & $<2 \mathrm{e}-16$ & $<2 \mathrm{e}-16$ & $<2 \mathrm{e}-16$ \\
\hline Rate & 3.5624 & 0.2740 & 0.2888 \\
\hline Standard Error & 0.0929 & 0.0324 & 0.0200 \\
\hline P-Value & $<2 \mathrm{e}-16$ & $<2 \mathrm{e}-16$ & $<2 \mathrm{e}-16$ \\
\hline $\begin{array}{l}\text { Rate*(Indicator High } \\
\text { Rate Regime) }\end{array}$ & -3.4039 & -0.2236 & -0.2117 \\
\hline Standard Error & 0.0896 & 0.0286 & 0.0151 \\
\hline P-Value & $<2 \mathrm{e}-16$ & $6.44 \mathrm{E}-15$ & $<2 \mathrm{e}-16$ \\
\hline Adjusted R-Squared & 0.1853 & 0.0125 & 0.0303 \\
\hline
\end{tabular}

are tabulated in Table 4.2, and show that the coefficient estimate on the rate variable is positive, but interaction rate variable is of opposite sign and comparable magnitude. This result is consistent with yields being independent of volatility in high rate regimes, but positively related in low rates regimes.

In order to calibrate our model to the data, we specify a suitable distribution as a mixture of log-normal and normal ("MNLN") distributions model for the rates. This is defined by:

$$
\operatorname{M~NLN}\left(Y_{t}(\tau) \mid P_{N}, \boldsymbol{\Theta}_{\tau}^{N}, \Theta_{\tau}^{L N}\right)=P_{N} \mathrm{~N}\left(Y_{t}(\tau) \mid \Theta_{\tau}^{N}\right)+\left(1-P_{N}\right) \operatorname{L~N}\left(Y_{t}(\tau) \mid \Theta_{\tau}^{L N}\right)
$$

Where $P_{N}$ denotes the probability (or proportion) of normal data, N (•) a normal density function, $\boldsymbol{\Theta}_{\tau}^{N}$ the parameters of the latter, $\mathrm{L} \mathrm{N}(\bullet)$ a log-normal density function, and $\boldsymbol{\Theta}_{\tau}^{{ }_{\tau} N}$ are the parameters of the latter. We built a function in $\mathrm{R}$ to calibrate the parameters of this model by the method of maximum likelihood estimation (MLE):

$$
\left(\hat{P}_{N}, \hat{\boldsymbol{\Theta}}_{\tau}^{N}, \hat{\boldsymbol{\Theta}}_{\tau}^{L N}\right)^{M L E}=\underset{\left(P_{N}, \boldsymbol{\Theta}_{\tau}^{N}, \boldsymbol{\Theta}_{\tau}^{L N}\right)}{\arg \max }\left\{\sum_{t=1}^{T} \log \left(\operatorname{MNLN}\left(P_{N}, \boldsymbol{\Theta}_{\tau}^{N}, \boldsymbol{\Theta}_{\tau}^{L N} \mid Y_{t}(\tau)\right)\right)\right\}
$$

Finally, we optimally calibrate the smoothing parameter by the following p0roceedure. First, we determine the threshold for the high-interest rate environment, denoted by $Y_{t}^{*}(\tau)$, as the quantile of the fitted MNLN rate distribution where confidence level is set to the MLE estimate of the probability of a log-normal distribution $1-\hat{P}^{M L E}$, solving:

$$
1-\hat{P}_{N}^{M L E}={ }_{M E E} \widehat{\mathrm{DMNLN}}^{-1}\left(Y_{t}^{*}(\tau) \mid\left(\hat{P}_{N}, \hat{\boldsymbol{\Theta}}_{\tau}^{N}, \hat{\boldsymbol{\Theta}}_{\tau}^{L N}\right)^{M L E}\right)
$$

Where ${ }^{M E E} \widehat{\mathrm{DMNLN}}^{-1}(\bullet)$ denotes the estimated distribution function:

$$
{ }_{M L E} \widehat{\mathrm{DMNLN}}^{-1}\left(x \mid\left(\hat{P}_{N}, \hat{\boldsymbol{\Theta}}_{\tau}^{N}, \hat{\boldsymbol{\Theta}}_{\tau}^{L N}\right)^{M L E}\right)=\int_{0}^{x} M_{E} \widehat{\operatorname{MNLN}}^{-1}\left(u \mid\left(\hat{P}_{N}, \hat{\boldsymbol{\Theta}}_{\tau}^{N}, \hat{\boldsymbol{\Theta}}_{\tau}^{L N}\right)^{M L E}\right) d u
$$

Assuming that shadow rates are approximately Gaussian, in a second stage we maximize the Normal log-likelihood function of $X_{t}(\tau)$ as a function of $Y_{t}(\tau)$ in equation (3.7) over $\eta$ and $\Theta^{\eta}$ :

$$
\left.\left(\hat{\eta}, \hat{\boldsymbol{\Theta}}_{\tau}^{\eta}\right)^{M L E}=\underset{\left(\eta, \mathbf{\Theta}_{\tau}^{\eta}\right)}{\arg \max }\left\{\sum_{t=1}^{T} \log \mid \mathrm{N}\left(\eta, \boldsymbol{\Theta}_{\tau}^{\eta} \mid I_{Y_{t}(\tau) \geq Y_{t}^{*}(\tau)} Y_{t}(\tau)+I_{Y_{t}(\tau)<Y_{t}^{*}(\tau)} \eta\left(\ln \left(\frac{Y_{t}(\tau)}{\eta}\right)+1\right)\right)\right\}\right\}
$$


Table4.3. Maximum Likelihood Estimation of Mixture of Normal and Log-Normal Model and Inverse Call Transformation Smoothing Parameters - Daily U.S. Treasury Yields Time Series (1, 2 and 5 Year Maturities January, 1990 to June, 2016)

\begin{tabular}{|c|c|c|c|c|c|c|}
\hline & & & & \begin{tabular}{|l|}
1 year U.S \\
Treasury Yield
\end{tabular} & \begin{tabular}{|l|}
2 year U.S \\
Treasury Yield
\end{tabular} & \begin{tabular}{|l|}
5 year U.S \\
Treasury Yield \\
\end{tabular} \\
\hline \multirow{16}{*}{$\begin{array}{l}\text { First stage- } \\
\text { interest rates } \\
\text { calibration }\end{array}$} & \multirow{6}{*}{ Normal } & \multirow{3}{*}{ Mean } & Estimate & 0.0436 & 0.0505 & 0.0543 \\
\hline & & & Standard Error & $2.74 \mathrm{E}-04$ & $2.62 \mathrm{E}-04$ & $2.62 \mathrm{E}-04$ \\
\hline & & & P-value & $0.0 \mathrm{E}+00$ & $0.00 \mathrm{E}+00$ & $0.00 \mathrm{E}+00$ \\
\hline & & \multirow{3}{*}{$\begin{array}{l}\text { Standard Devia- } \\
\text { tion }\end{array}$} & Estimate & 0.0181 & 0.0154 & 0.0151 \\
\hline & & & Standard Error & 0.0002 & 0.0002 & 0.0002 \\
\hline & & & P-value & $0.0 \mathrm{E}+00$ & $0.0 \mathrm{E}+00$ & $0.0 \mathrm{E}+00$ \\
\hline & \multirow{6}{*}{ Log-Normal } & \multirow{3}{*}{ Mean } & Estimate & -6.0754 & -5.0119 & -4.0878 \\
\hline & & & Standard Error & $1.57 \mathrm{E}-02$ & $1.70 \mathrm{E}-02$ & $1.30 \mathrm{E}-02$ \\
\hline & & & P-value & $0.0 \mathrm{E}+00$ & $0.00 \mathrm{E}+00$ & $0.00 \mathrm{E}+00$ \\
\hline & & \multirow{3}{*}{$\begin{array}{l}\text { Standard Devia- } \\
\text { tion }\end{array}$} & Estimate & 0.9437 & 0.7108 & 0.4983 \\
\hline & & & Standard Error & 0.0284 & 0.0127 & 0.0093 \\
\hline & & & P-value & $0.0 \mathrm{E}+00$ & $0.00 \mathrm{E}+00$ & $0.00 \mathrm{E}+00$ \\
\hline & \multirow{3}{*}{\multicolumn{2}{|c|}{ Probability of Normal Regime }} & Estimate & 0.7199 & 0.6415 & 0.6562 \\
\hline & & & Standard Error & $2.84 \mathrm{E}-02$ & $2.76 \mathrm{E}-02$ & $3.01 \mathrm{E}-02$ \\
\hline & & & P-value & $0.0 \mathrm{E}+00$ & $0.00 \mathrm{E}+00$ & $0.00 \mathrm{E}+00$ \\
\hline & \multicolumn{3}{|c|}{ Log-Likelihood value } & $-1.8 \mathrm{E}+04$ & $-1.75 \mathrm{E}+04$ & $-1.69 \mathrm{E}+04$ \\
\hline \multirow{10}{*}{$\begin{array}{l}\text { Second } \\
\text { stage- } \\
\text { Shadow rates } \\
\text { calibration }\end{array}$} & \multirow{3}{*}{\multicolumn{2}{|c|}{ Leg Linetilivou vaiue }} & Estimate & 0.0321 & 0.0349 & 0.0416 \\
\hline & & & Standard Error & $2.51 \mathrm{E}-04$ & 1.19E-04 & 7.53E-04 \\
\hline & & & P-value & $0.0 \mathrm{E}+00$ & $0.00 \mathrm{E}+00$ & $0.00 \mathrm{E}+00$ \\
\hline & \multirow{3}{*}{\multicolumn{2}{|c|}{ Standard Deviation }} & Estimate & 0.0241 & 0.0245 & 0.0221 \\
\hline & & & Standard Error & $3.02 \mathrm{E}-04$ & $2.05 \mathrm{E}-04$ & $1.04 \mathrm{E}-03$ \\
\hline & & & $\mathrm{P}$-value & $0.0 \mathrm{E}+00$ & $0.00 \mathrm{E}+00$ & $0.00 \mathrm{E}+00$ \\
\hline & \multirow{3}{*}{\multicolumn{2}{|c|}{$\begin{array}{l}\text { Inverse Call Transformation } \\
\text { smoothing Parameter }\end{array}$}} & \begin{tabular}{|l|} 
Estimate \\
\end{tabular} & 0.0022 & 0.0059 & 0.0143 \\
\hline & & & Standard Error & $4.48 \mathrm{E}-04$ & $2.83 \mathrm{E}-03$ & $1.90 \mathrm{E}-03$ \\
\hline & & & P-value & $4.6 \mathrm{E}-07$ & $1.84 \mathrm{E}-02$ & $2.26 \mathrm{E}-14$ \\
\hline & \multicolumn{3}{|c|}{ Log-Likelihood value } & $-1.53 \mathrm{E}+04$ & $-1.52 \mathrm{E}+04$ & $-1.59 \mathrm{E}+04$ \\
\hline
\end{tabular}

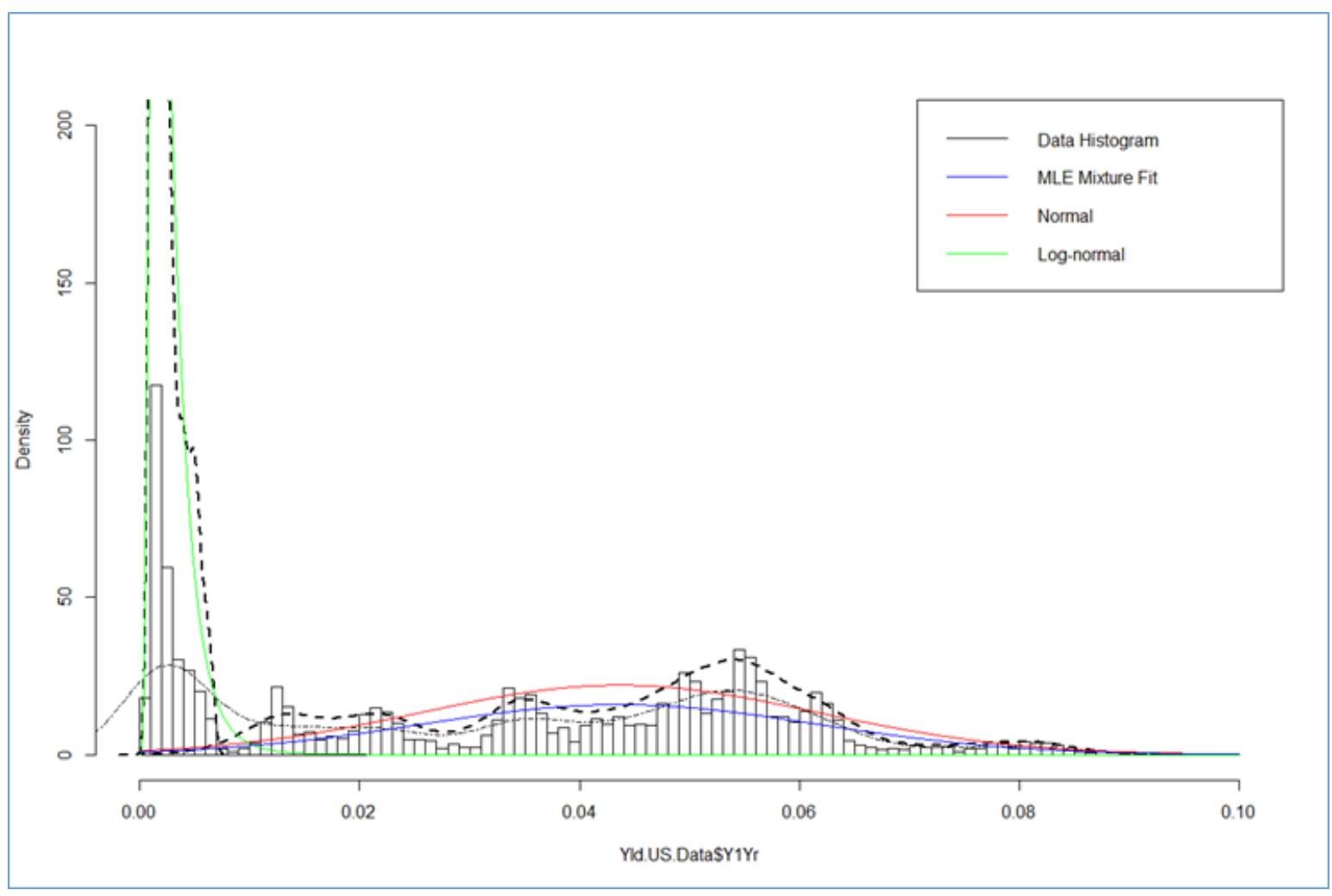

Figure4.3.Maximum Likelihood Estimation of Mixture of Normal and Log-Normal Model Fitted Densities - Daily U.S. Treasury Yields (1 Year Maturity - January, 1990-June, 2016) 


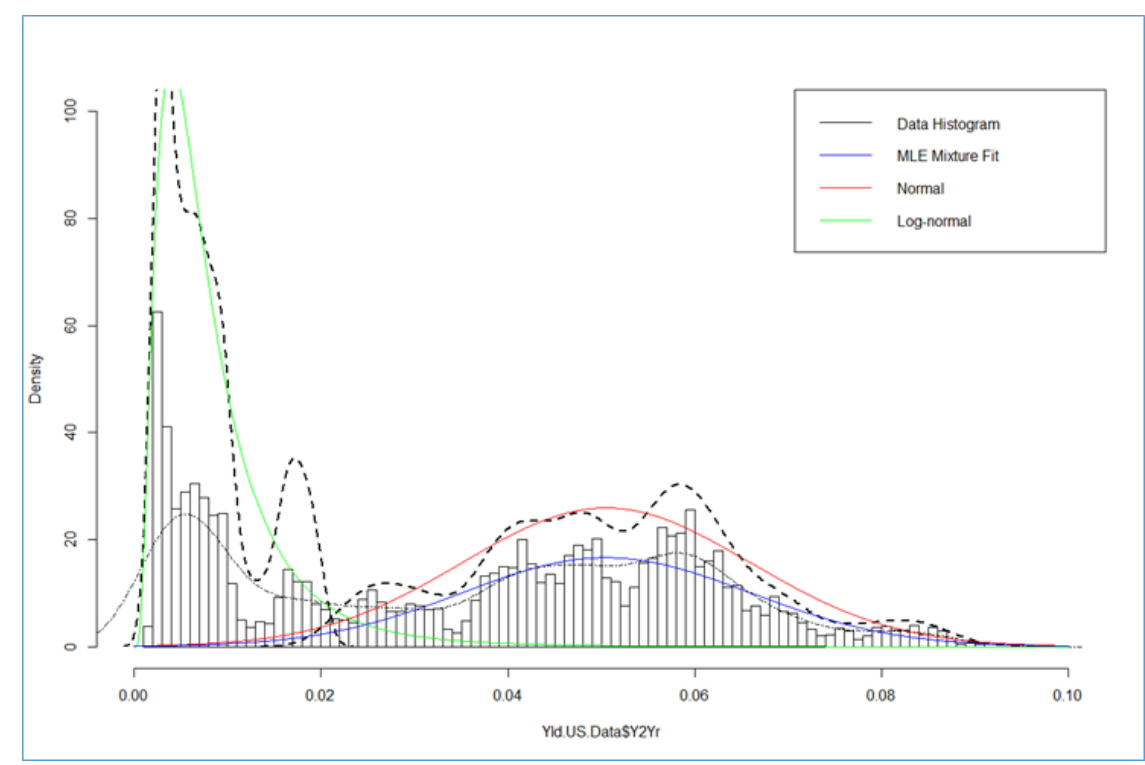

Figure4.4. Maximum Likelihood Estimation of Mixture of Normal and Log-Normal Model Fitted Densities - Daily U.S. Treasury Yields (2 Year Maturity - January, 1990-June, 2016)

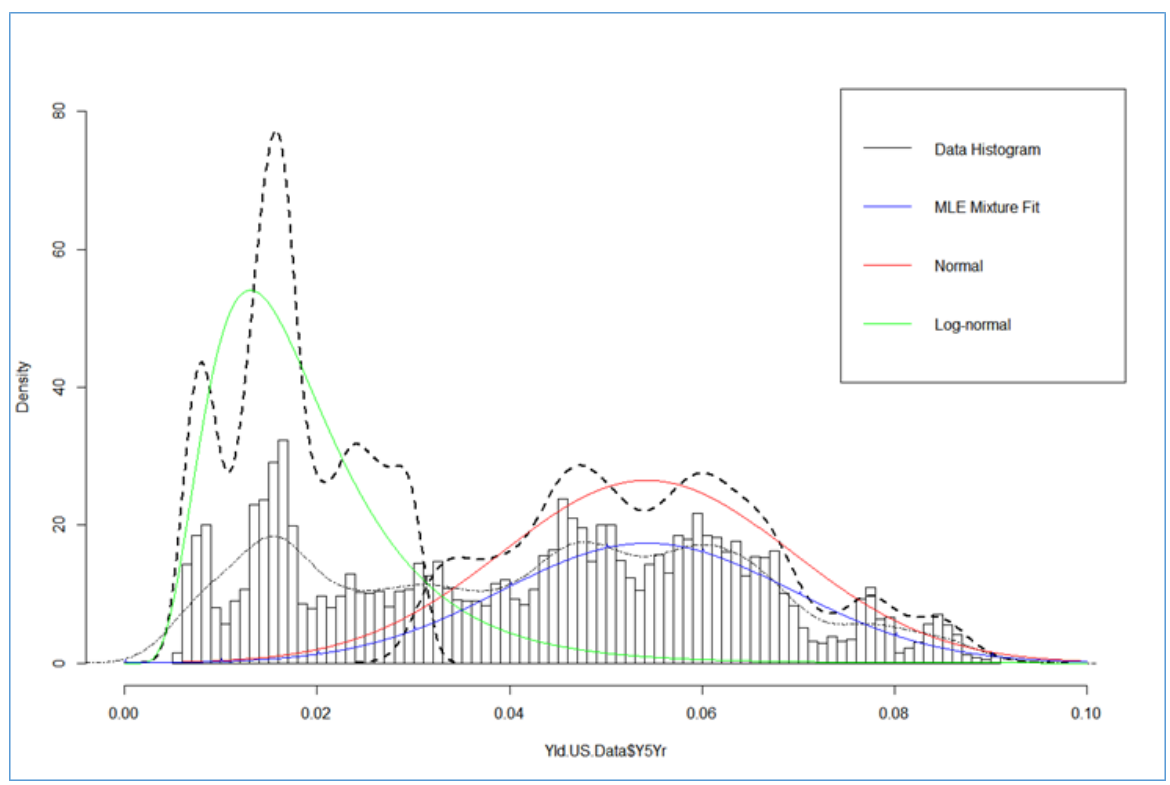

Figure4.5. Maximum Likelihood Estimation of Mixture of Normal and Log-Normal Model Fitted Densities - Daily U.S. Treasury Yields (5 Year Maturity - January, 1990-June, 2016)

Where $\boldsymbol{\Theta}^{\eta}=\left(\mu^{x}, \sigma^{x}\right)$ are the parameters of the Gaussian distributed shadow rates and where $I_{x \geq c}=\left\{\begin{array}{ll}1 & \text { if } \quad x \geq c \\ o & \text { if } \quad x<c\end{array}\right.$ is the indicator function. The results of the estimation are tabulated in Table 4.3 and the fitted mixtures of normal and log-normal distributions are shown in Figures 4.3-4.5. The time series and data histograms of estimated shadow rates based upon the optimal inverse call transformation smoothing parameters are shown in Figures 4.6-4.8.

We now present an applications of the inverse-call transformation to the risk management of fixed income portfolios, wherein practitioners measure and manage the P\&L of portfolios that are affected by the term structure of interest rates. We consider a portfolio that is exposed to the vector term structure of interest rates $\mathbf{Y}_{t} \sim\left(Y_{t}\left(\tau_{1}\right), \ldots, Y_{t}\left(\tau_{\bar{n}}\right)\right)$ where $\left(\tau_{n}\right)_{n=1}^{\bar{n}}$ are the set of relevant tenors. We assume that the portfolio's P\&L is a deterministic function of the path over 
the investment horizon ${ }^{u}$ of the interest rates stemming from the current term structure $\mathbf{Y}_{t}$, which can be summarized as the path of the term structure of interest rates over the horizon with a grid of intermediate steps:

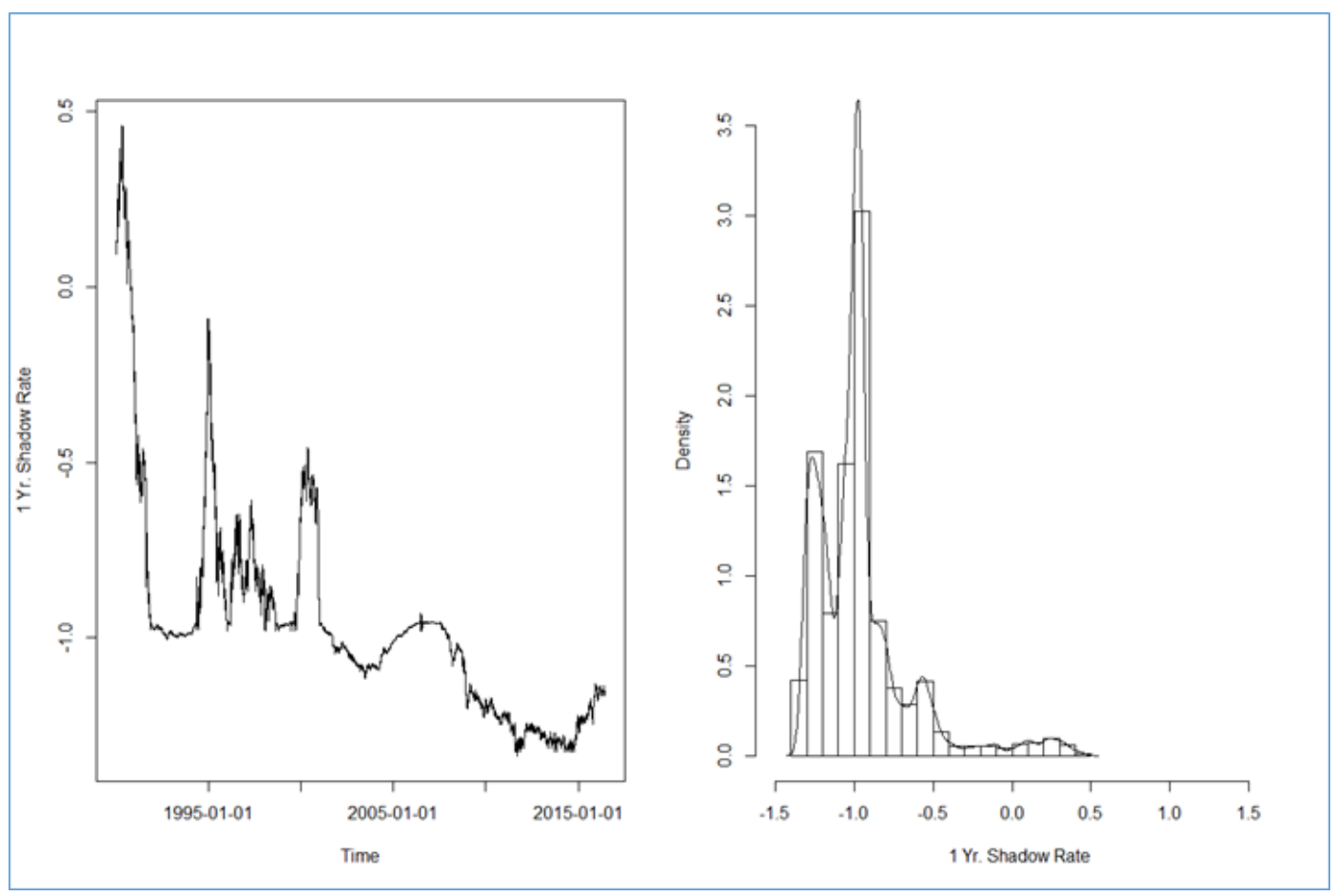

Figure4.6. Time Series and Data Histograms Shadow Rates Based Upon of Maximum Likelihood Estimation Optimal Inverse Call Transformation Smoothing Parameters - Daily U.S. Treasury Yields (1 Year Maturity January, 1990-June, 2016)

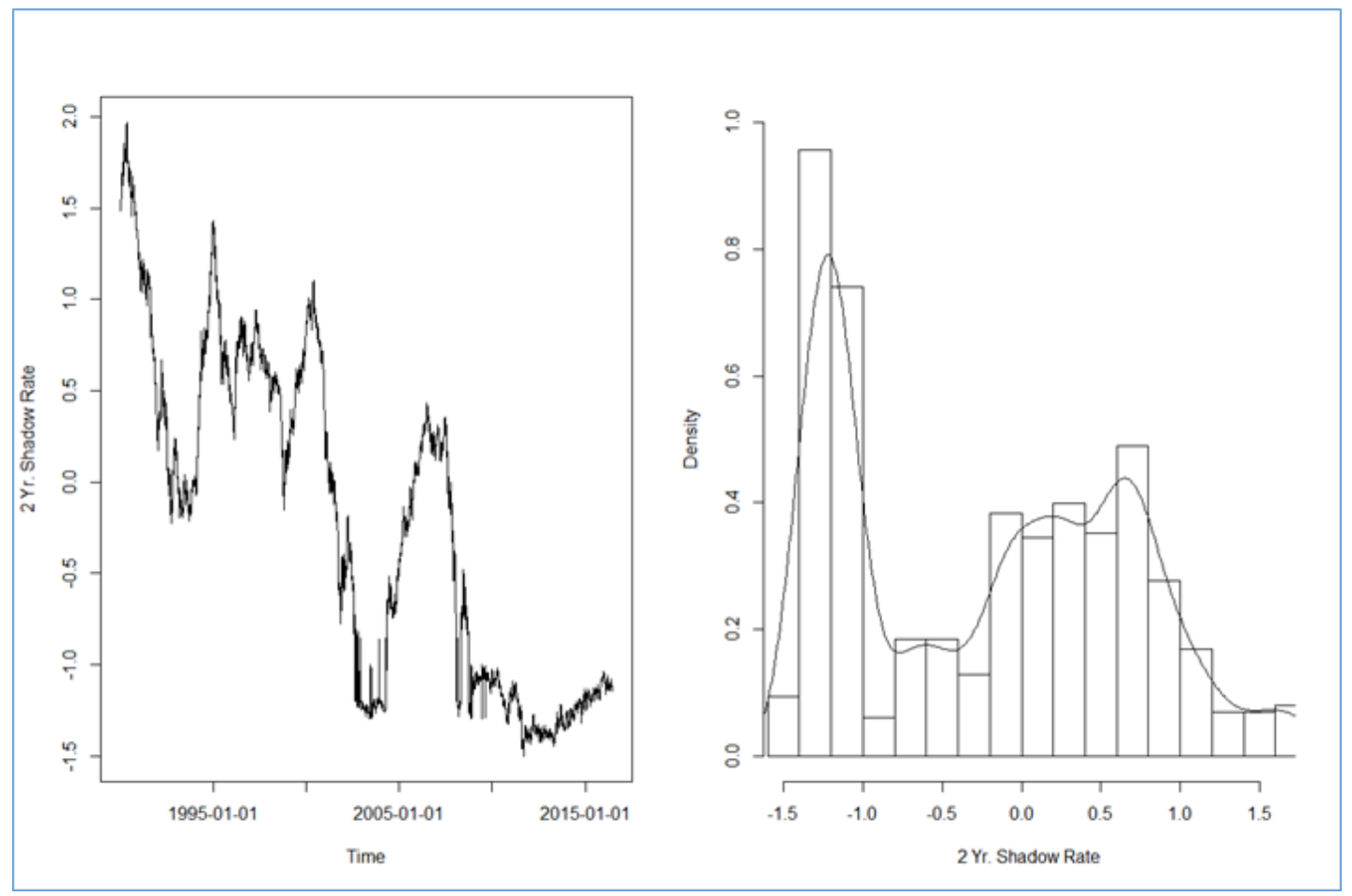

Figure4.7. Time Series and Data Histograms Shadow Rates Based Upon of Maximum Likelihood Estimation Optimal Inverse Call Transformation Smoothing Parameters - Daily U.S. Treasury Yields (2 Year Maturity January, 1990-June, 2016) 


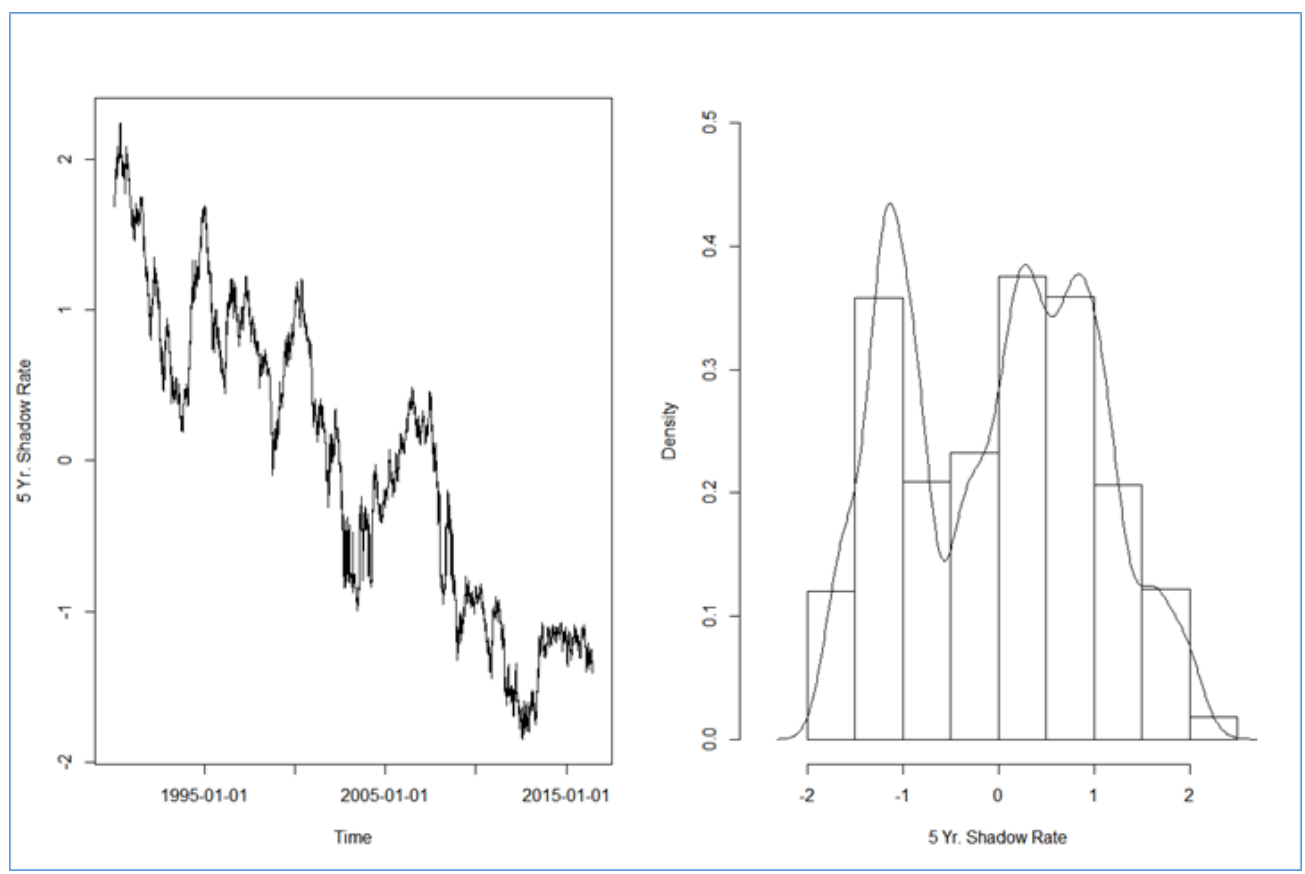

Figure4.8. Time Series and Data Histograms Shadow Rates Based Upon of Maximum Likelihood Estimation Optimal Inverse Call Transformation Smoothing Parameters - Daily U.S. Treasury Yields (5 Year Maturity January, 1990-June, 2016)

$$
\mathbf{Y}_{\bar{t} \rightarrow u} \mid \mathbf{Y}_{\bar{t}}=\left(\mathbf{Y}_{\bar{t}}\left|\mathbf{Y}_{\bar{t}+1}\right| \cdots \mathbf{Y}_{\bar{t}+u} \mid\right)=\left\{\begin{array}{cccc}
y_{1, \bar{t}} & y_{1, \bar{t}+1} & \cdot & y_{1, \bar{t}+u} \\
y_{2, \bar{t}} & y_{2, \bar{t}+1} & \cdot & y_{2, \bar{t}+u} \\
\cdot & \cdot & \cdot & \\
y_{\bar{n}, \bar{t}} & y_{\bar{n}, \bar{t}+1} & \cdot & y_{\bar{n}, \bar{t}+u}
\end{array}\right)
$$

A common assumption in modeling a portfolio's daily P\&L is to model the term structure of rate increments to be i.i.d., as in the framework of Litterman and Scheinkman (1991) based upon movements in the term structure of interest rates and bond returns, wherein they shock only the first three principal components. In the case of most investment horizon lengths we need to estimate the distribution of each interest rate's path as in equation 4.6. This involves a transformation of the raw yields into homogeneous risk drivers that have the invariance property, meaning that they have stable distributions over time and are the sole source of randomness for the risk drivers. Therefore, we collect the observed time series of the term structure $\left\{\mathbf{Y}_{t}\right\}_{t \leq \bar{t}}$ and then compute the time series of the suitable risk drivers denoted by $\left\{\mathbf{z}_{t}\right\}_{t \leq \bar{t}}$, which will be defined by the observed term structure in the normal model (NM), the log-rates in the log-normal model (LNM) and the shadow rates defined herein in the mixture of normal and log-normal models (MNLNM):

$\mathbf{Y}_{t} \rightarrow \mathbf{Z}_{t} \sim \begin{cases}\mathbf{X}_{t}=c_{\eta}^{-1}\left(\mathbf{Y}_{t}\right) & \text { if } \mathrm{M} \mathrm{NLM} \mathrm{N} \\ \mathbf{Y}_{t} & \text { if } \mathrm{NM} \\ \log \left(\mathbf{Y}_{t}\right) & \text { if } \mathrm{L} \mathrm{N} \mathrm{M}\end{cases}$

We then fit the econometric process of the risk drivers to the realized time series obtained in order to extract the invariants. In order to capture the relationships across the tenors of the term structure, the benchmark model we consider, the DCC of Engle and Sheppard (2001) and Engle (2002), is a generalization of the constant conditional correlation model of Bollerslev (1990), which can be written as: 


$$
\begin{aligned}
& \mathbf{H}_{t}=\mathrm{E}_{t-1}\left(\left(\mathbf{Z}_{t}-E_{t-1}\left(\mathbf{Z}_{t}\right)\right)\left(\mathbf{Z}_{t}-E_{t-1}\left(\mathbf{Z}_{t}\right)\right)^{T}\right)=\mathbf{D}_{t} \mathbf{R}_{t} \mathbf{D}^{T}, \\
& \mathbf{D}_{t}=\operatorname{diag}\left(\sqrt{h_{i, t}}\right) \quad i=1, \ldots, \bar{n}
\end{aligned}
$$

where $\mathbf{H}_{t}$ is the variance-covariance matrix and $h_{i, t}$ are a series of univariate GARCH models. While there are various ways in which to parameterize the conditional correlation matrix $\mathbf{R}_{t}$ the one advocated by Engle (2002) is:

$$
\mathbf{R}_{t}=\operatorname{diag}\left(\mathbf{Q}_{t}\right)^{-1} \mathbf{Q}_{t} \operatorname{diag}\left(\mathbf{Q}_{t}\right)^{-1}
$$

This follows the M-GARCH specification for $\mathbf{Q}_{t}$ of Ding and Engle (2001), which guarantees its positive semi-definiteness in certain conditions. Engle (2002) shows that this is equivalent to expressing its elements as univariate $\mathrm{GARCH}(1,1)$ processes:

$$
q_{i j, t}=\bar{\rho}_{i, j}+\alpha\left(\varepsilon_{i, t} \varepsilon_{j, t}-\bar{\rho}_{i, j}\right)+\beta\left(q_{i j, t-1}-\bar{\rho}_{i, j}\right) \quad i, j=1, \ldots \bar{n}
$$

where $q_{i j, t}$ is the unconditional correlation between the errors terms $\varepsilon_{i, t}$ and $\varepsilon_{j, t}$, producing the correlation estimator:

$$
\rho_{i j, t}=\frac{q_{i j, t}}{\sqrt{q_{i i, t} q_{j j, t}}} i, j=1, \ldots \bar{n}
$$

It is shown in Engle and Sheppard (2001) and Engle (2002) that the likelihood function in the DCC model is the sum of the individual GARCH volatilities and a correlation term. While Aielli (2009) shows that under certain conditions the DCC may not be asymptotically unbiased, in finite samples this may not be material. We show the estimated conditional correlations for the three models in Equation 4.7 for the three tenors under consideration in Figures 4.9 through 4.11 .

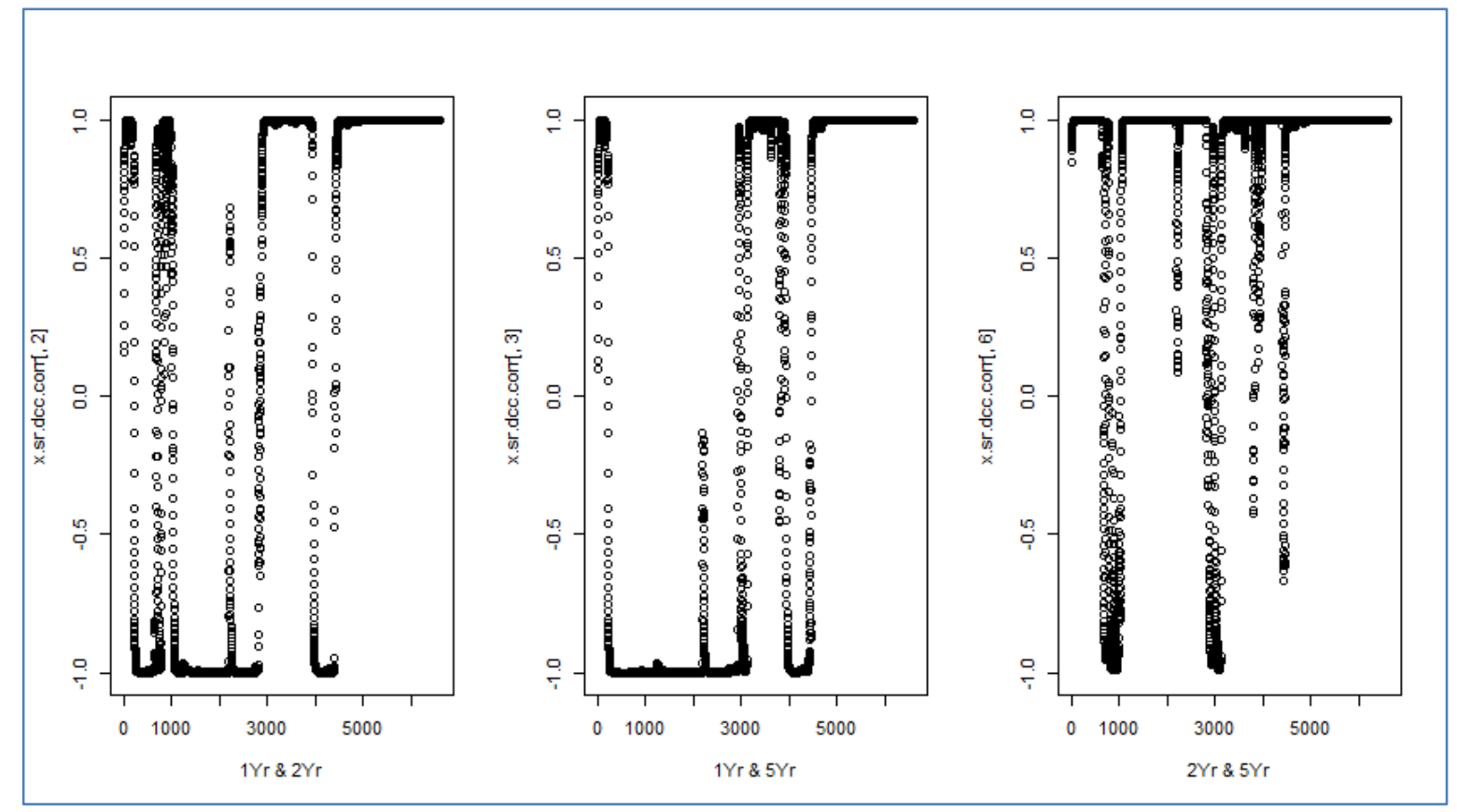

Figure 4.9. Dynamic Conditional Correlations (DCC) between MNLN Model Shadow Rates - Daily U.S. Treasury Yields (1, 2, and 5 Year Maturities: January, 1990 -June, 2016) 


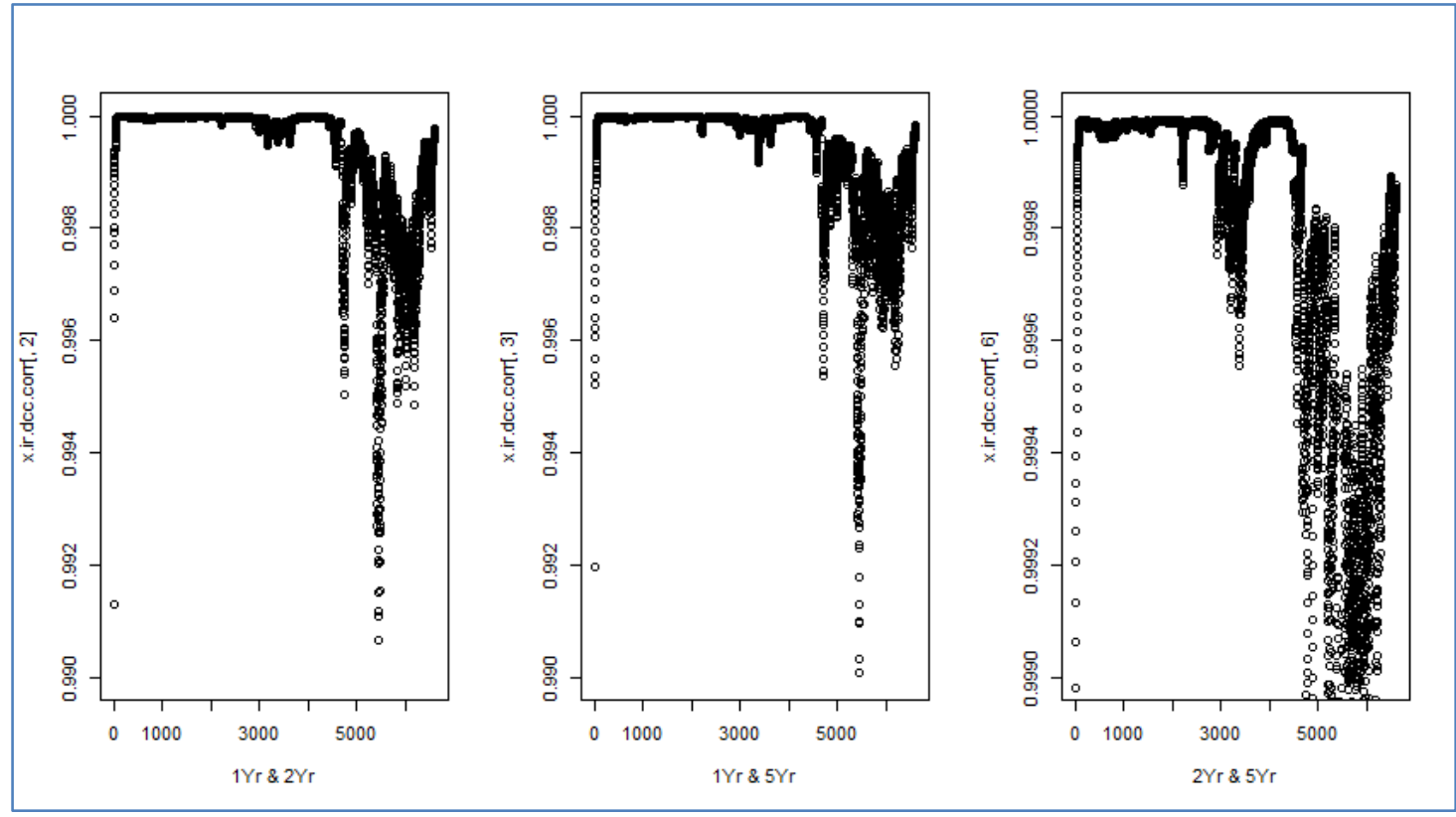

Figure4.10. Dynamic Conditional Correlations (DCC) between Normal Model Rates - Daily U.S. Treasury Yields (1, 2, and 5 Year Maturities: January, 1990 -June, 2016)

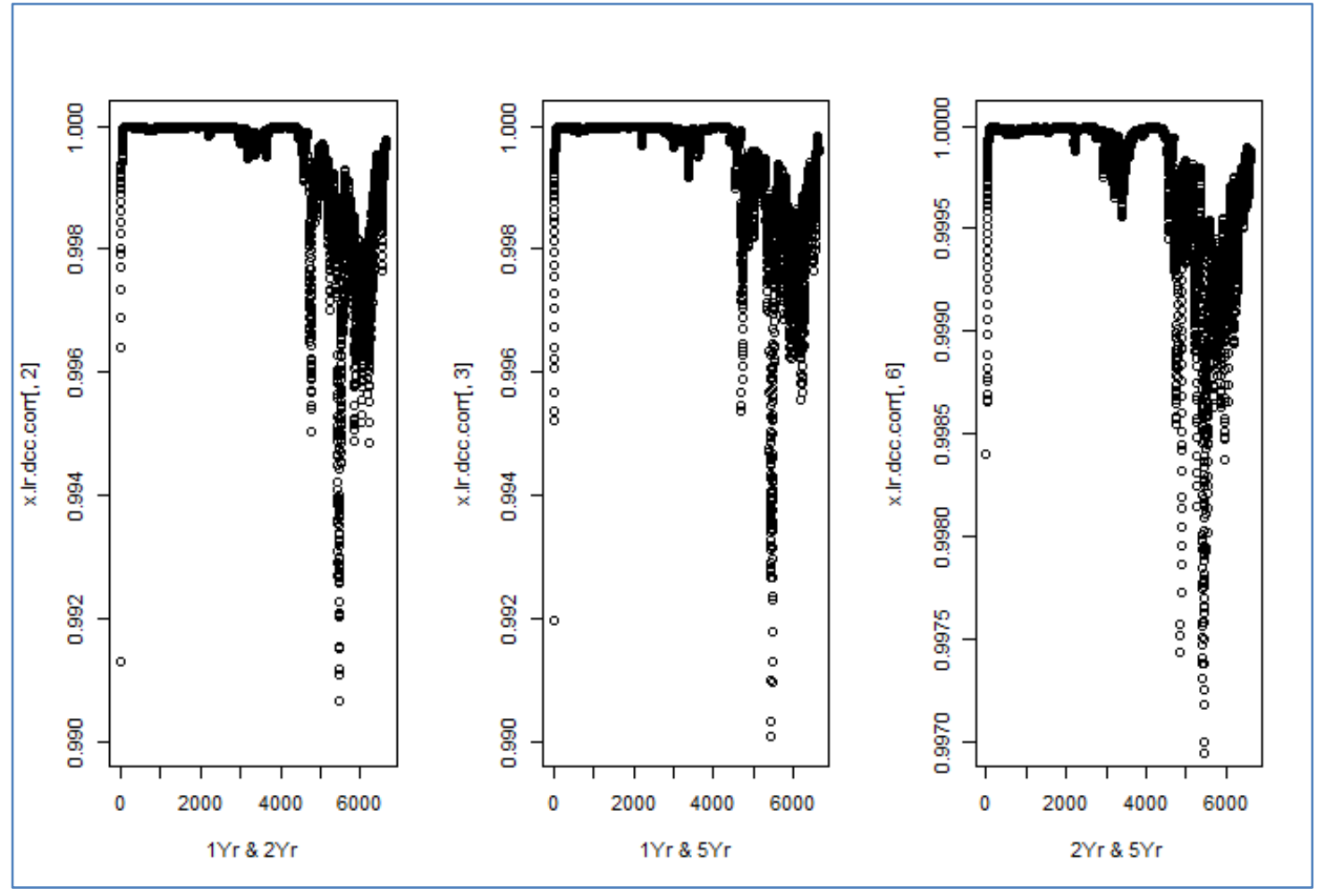

Figure4.11. Dynamic Conditional Correlations (DCC) between Log-Normal Model Logarithmic Rates - Daily U.S. Treasury Yields (1, 2, and 5 Year Maturities: January, 1990 -June, 2016)

We observe that the estimated dynamic correlation are very different for the MLNN model shadow rates as compared to either the NM or LNM raw or log rates - the former vary widely over time between minus and positive one, whereas the latter vary very narrowly near positive one. This is an important result, as it shows that the shadow rates are better able to capture the capture the time variation in the dependency structure across the yield curve, whereas raw rates or their logarithms as risk factors convey a misleading impression that rates are almost always perfectly correlated. 
As a final exercise, we simulate rate distributions from the fitted DCC model, with risk drivers from each of the models under consideration. We set the simulation horizon to 1 year with daily time steps for 100,000 simulation paths. The results of the simulation are shown in Figures 4.12 through 4.14. It is observed that each model produces a rather differing shaped distribution. The MNLN model with shadow rates as risk drivers are able to capture tail behavior well in excess of historical observations, extending out as far as $12 \%$ across maturities, and also exhibiting pro-found peakedness and bi-modality. On the other hand, the normal model fails

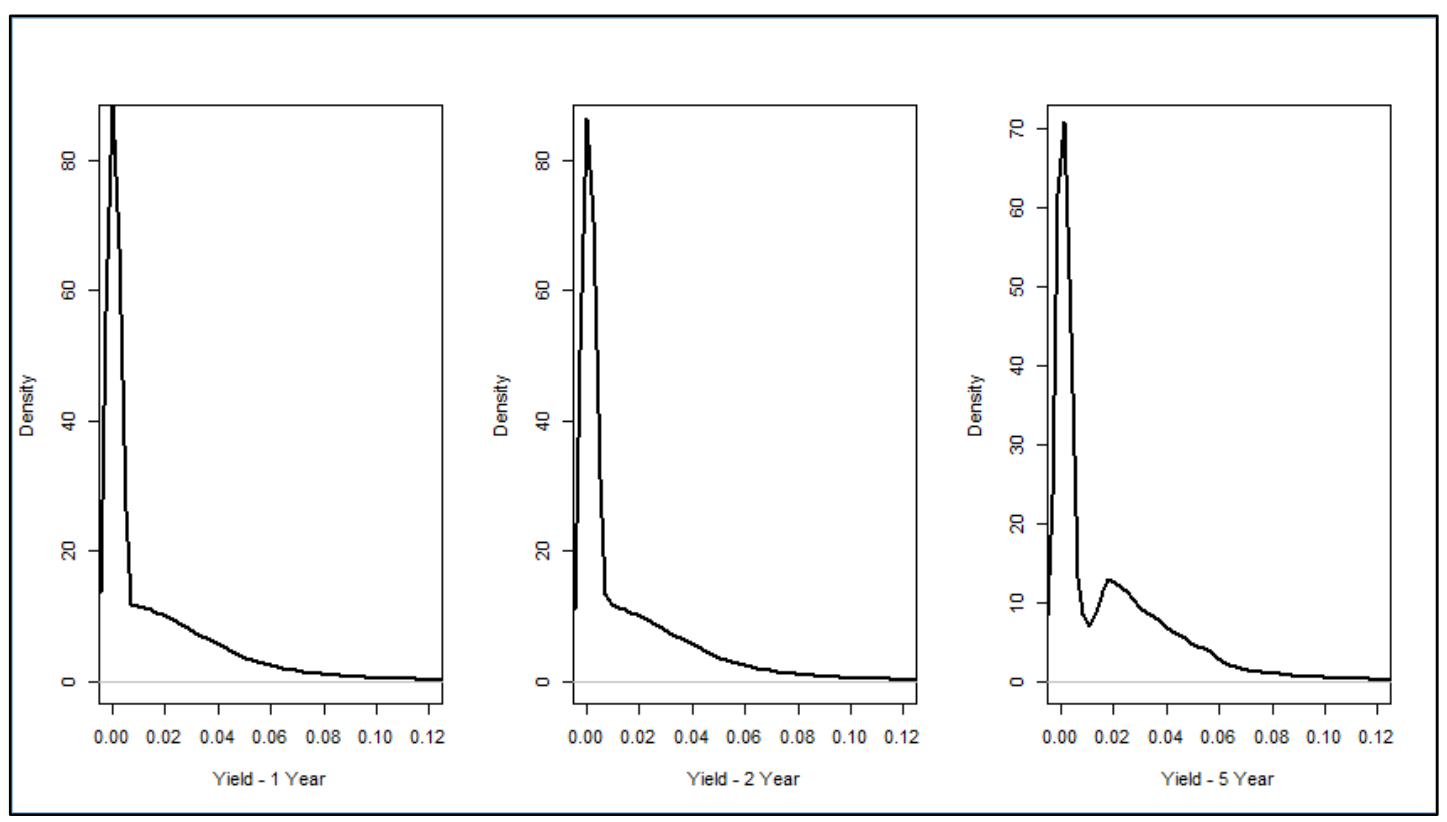

Figure4.12. Dynamic Conditional Correlations (DCC) 1-Year Simulated Daily U.S. Treasury Yields Distributions MNLN Model Shadow Rates - (1, 2, and 5 Year Maturities: January, 1990 -June, 2016)

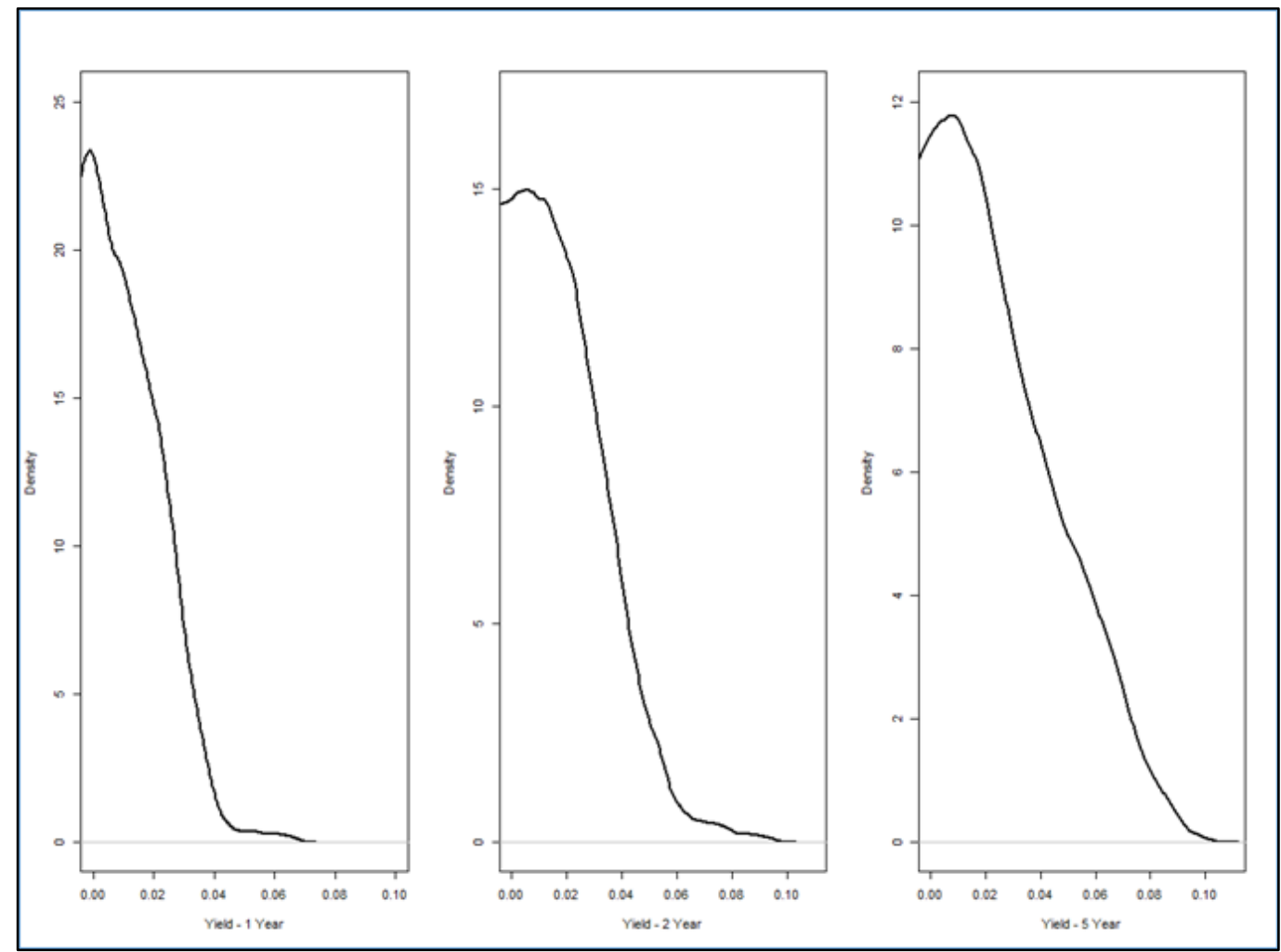

Figure4.13. Dynamic Conditional Correlations (DCC) 1-Year Simulated Daily U.S. Treasury Yields Distributions Normal Model Rates - (1, 2, and 5 Year Maturities: January, 1990 -June, 2016) 


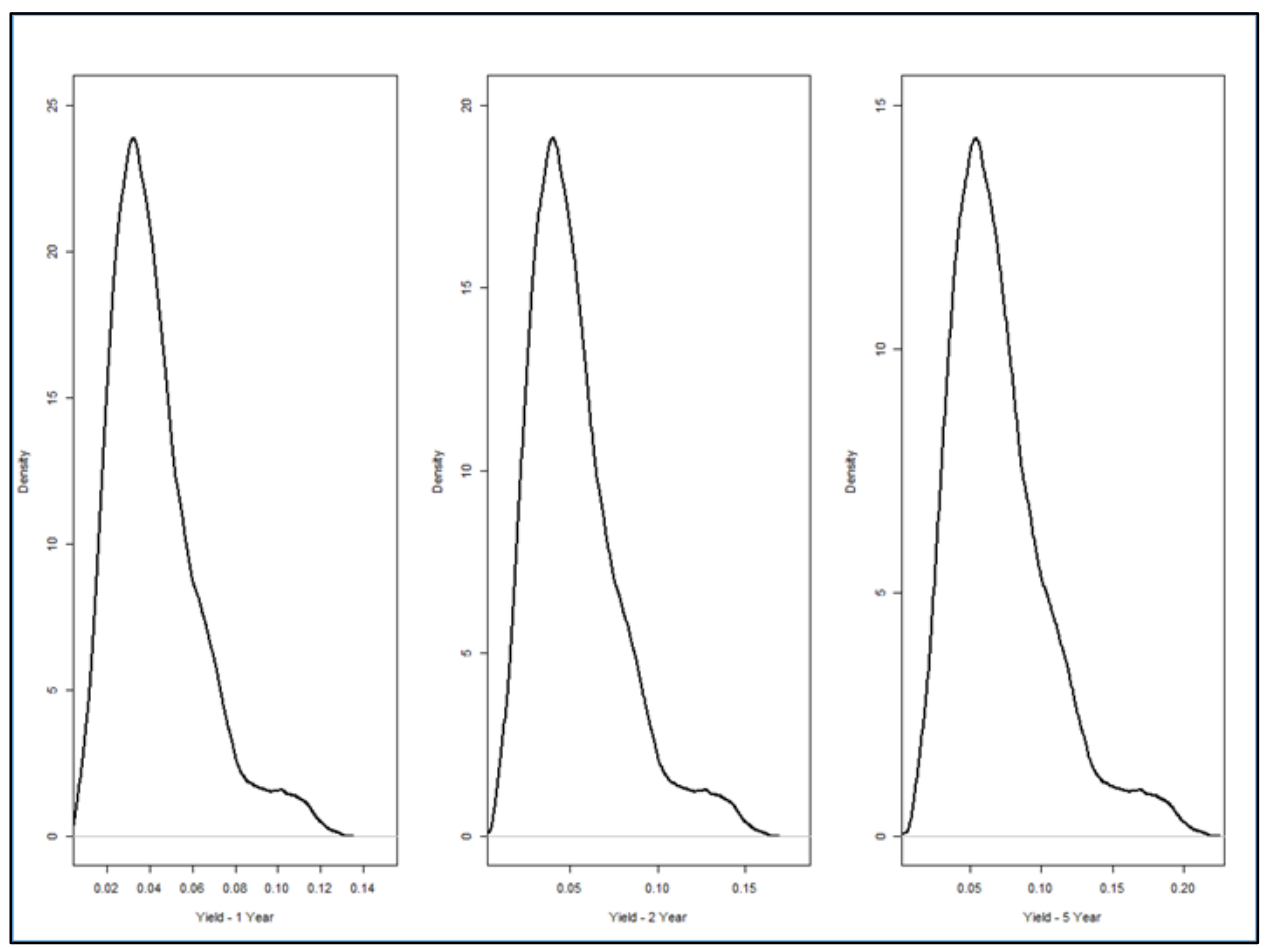

Figure4.14. Dynamic Conditional Correlations (DCC) 1-Year Simulated Daily U.S. Treasury Yields Distributions LN Model Log Rates - (1, 2, and 5 Year Maturities: January, 1990 -June, 2016)

to capture this fat-tailed behavior, barely reaching $10 \%$ at the 5 year maturity, or $7 \%$ at the 1 and 2 years maturities. In the log-normal model, we see the opposite extreme, with rates approaching explosive and unrealistic levels of $14 \%$ to $16 \%$ from the shortest to longest maturity, and also a failure to capture the bi-modality observed in history, with regard to the latter in particular the model near $0 \%$. We conclude that our mixture of normal and log-normal distributions model, utilizing optimally calibrated shadow rates as drivers, produces the most reasonable set of simulated 1 year rate distributions from the fitted DCC model as compared to the normal or log-normal model.

\section{CONCLUSION AND FUTURE DiRECTIONS}

In this study we have theoretically and empirically investigated a well-known phenomenon in the term structure literature, namely that the normal and log-normal distribution models are not consistent across high and low interest rate regimes. This has created challenges for building models to measure and manage interest rate risk, and we have proposed a practical solution to solving this problem, based upon the theory of Black (1995). We have utilized a so-called "inverse-call transformation" methodology, in order to derive what we have termed "shadow rates" as underlying risk factors driving the observed term structure of interest rates. Consistent with prior literature, we have not only shown this approach to be more appropriate than the standard models for the purposes forecasting and risk management with respect to interest rate sensitive portfolios, but we have also proposed a tractable methodology. We extended the literature by calibrating optimal shadow rates to the U.S. default free term structure (1,2 and 5 year maturities), and then by modeling them in a practical and state of the art econometric methodology, the multivariate DCC framework. We have applied the results to an interest rate risk management exercise, thereby providing a useful risk management tool for both risk managers and their prudential supervisors. The conclusion was that our mixture of normal and log-normal distributions model, utilizing optimally calibrated shadow rates as drivers, produces the most reasonable set of simulated 1 year rate distributions from the fitted DCC model as compared to either the normal or log-normal model. Specifically, a 1 year simulation of our mixture of normal and log-normal models, utilizing shadow rates as invariant risk drivers as 
opposed to either rates or logarithmic rates in the normal or log-normal model, respectively, is better able to capture fat-tails at reasonable rate levels as well as bi-modality of the rates distribution.

There are several fruitful avenues along which we may extend this research:

- Different fixed income instruments

- A wider array of maturities

- Alternative currencies

- Consideration of mixtures of distributions beyond normal or log-normal

- Applications of the methodology to pricing interest rate derivatives

- Development of a mechanism to model negative real rates

\section{REFERENCES}

Aielli, G.P., 2009. “Dynamic Conditional Correlations: On Properties and Estimation.” Working paper. University of Florence.

Bachelier, L. 1900. "Théorie de la Spéculation." Annales Scientifiques de l'École Normale Supérieure, 3 (17): 21-86.

Baliakin, A., A. Egorov, and H. Li. 2005. "Pricing Interest Rate Caps in a Generalized Affine Model with Stochastic Volatility and Correlation: Empirical Evidence.” EFMA 2006 Electronic Proceedings Papers (December).

Barnes, D. 2015. "Small Banks Face Rate Options Valuation Model Change.” Risk, December 17th.

Becker, L. 2016. "Banks Fear Huge Losses on Bond Repacks in Japan.” Risk, May 16th.

Black, F.1976. "The Pricing of Commodity Contracts." Journal of Financial Economics 3: 167-179.

Black , F. 1995. "Interest Rates as Options.” Journal of Finance, 50(5): 1371-1376.

Bliss, R. 1997. "Movements in the Term Structure of Interest Rates." Economic Review (Federal Reserve Bank of Atlanta), 82 (4): 16-33.

Bollerslev, T. 1990. "Modeling the Coherence in the Short-run Nominal Exchange Rates: A Multivariate Generalized ARCH Model." Review of Economics and Statistics, 72: 498-505.

Collin-Dufresne, P., and R. Goldstein. 2002. "Stochastic Correlation and the Relative Pricing of Caps and Swaptions in a Generalized-Affine Framework." EFA Berlin Meetings, Berlin (August).

Cox, J.C., Ingersoll, J.E., and S.A. Ross. 1985. "A Theory of the Term Structure of Interest Rates." Econometrica, 53 (2): 385-407.

Dai, Q., and K. Singleton. 2000. "Specification Analysis of Affine Term Structure Models." Journal of Finance, 55 (5): 1943-1978.

Ding, Z., and Engle, R.F. 2001. "Large Scale Conditional Covariance Matrix Modeling, Estimation and Testing." Academy of Economics Papers, 29: 57-184.

Dothan, I.U. 1978. "On the Term Structure of Interest Rates." Journal of Financial Economics, 6: 59-69.

Duffie, D., and R. Kan. 1996. "A Yield-Factor Model of Interest Rates." Mathematical Finance, 6 (4): 379-406.

Duffee, G.R. 2002. "Term Premia and Interest Rate Forecasts in Affine Models." Journal of Finance, 57 (1): 405-443.

Engle, R. F. 2002. "Dynamic Conditional Correlation." Journal of Business and Economic Statistics, 20: 339-350. 
Engle,R.F., and K. Sheppard. 2001. "Theoretical and Empirical Properties of Dynamic Conditional Correlation Multivariate GARCH." NBER Working Paper 8554.

Feunou, B., and N. Meddahi. 2009. "Generalized Affine Models." Working paper (21 July): http://ssrn.com/abstract=1367033.

Goldstein, R.S. 2000. "The Term Structure of Interest Rates as a Random Field." Review of Financial Studies, 13 (2): 365-384.

Heath, D., R. Jarrow, and A. Morton. 1992. "Bond Pricing and the Term Structure of Interest Rates: A New Methodology for Contingent Claims Valuation.” Econometrica, (60) 1: 77-105.

Jacobs, Jr., M., 2001, “A Comparison of Fixed Income Valuation Models: Pricing and Econometric Analysis of Interest Rate Derivatives", Unpublished Doctoral Dissertation, The Graduate School and University Center of the City University of New York.

J.P. Morgan, 1996, “Risk Metrics TM-Technical Document (4th Edition)”, New York (December 19th).

Litterman, R., and J. Scheinkman. 1991. "Common Factors Affecting Bond Returns." Journal of Fixed Income, 1 (1): 54-61.

Liu, Q. 2007. 'Options' Prices under Arithmetic Brownian Motion and Their Implication for Modern Derivatives Pricing." Working paper (http://ssrn.com/abstract=959809).

Loregian, A., and A. Meucci. 2016. "Neither "Normal" nor "Lognormal": Modeling Interest Rates across All Regimes." Financial Analysts Journal 72 (3): 68-82.

Osborn, T. 2016. "SGX to Charge Negative Interest to Clearing Members." Risk, August 25th.

Soto, G.M. 2004. "Using Principal Component Analysis to Explain Term Structure Movements: Performance and Stability." Working paper (http://papers.ssrn.com/sol3/papers.cfm? abstract_ id $=985404$ ).

Vaghela, V. 2016. "US Dollar/Yen Basis Blows Out to -100 on Negative Rates." Risk, February 25 th.

Vasicek, O. 1977. "An Equilibrium Characterization of the Term Structure." Journal of Financial Economics, 5 (2): 177-188.

Citation: Michael Jacobs, Jr. "A Mixture of Distributions Model for the Term Structure of Interest Rates with an Application to Risk Management", American Research Journal of Business and Management; Volume 3, 2017; pp:1-17

Copyright (c) 2017 Michael Jacobs, Jr. This is an open access article distributed under the Creative Commons Attribution License, which permits unrestricted use, distribution, and reproduction in any medium, provided the original work is properly cited. 